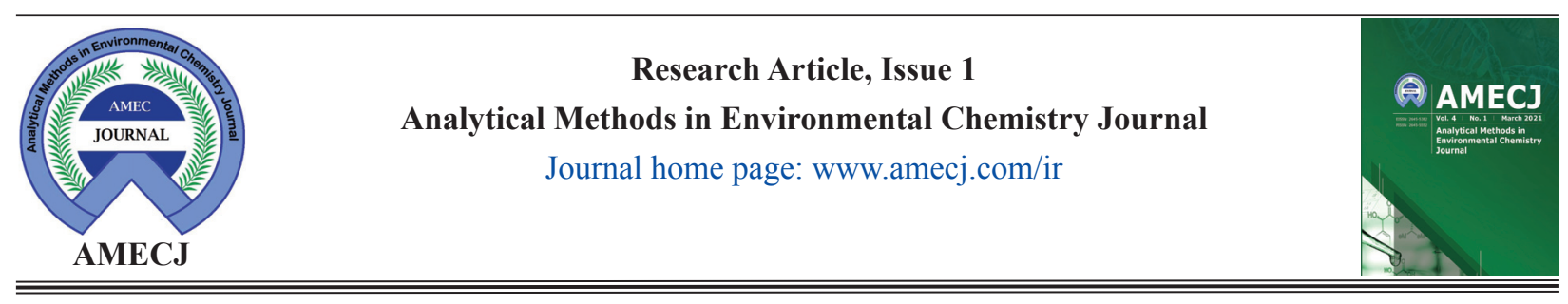

\title{
Separation and determination of cadmium in water samples based on functionalized carbon nanotube by syringe filter membrane-micro solid-phase extraction
}

\author{
Jamshid Rakhtshah a,* \\ ${ }^{a}$ Department of Inorganic Chemistry, Faculty of Chemistry, University of Tabriz, Tabriz, Iran
}

\section{A R T I C L E I N F O :}

Received 19 Nov 2020

Revised form 25 Jan 2021

Accepted 22 Feb 2021

Available online 28 Mar 2021

Keywords:

Cadmium,

Separation,

Water,

Functionalized carbon nanotubes, Syringe filter membrane micro solid phase extraction,

Atom trap flame atomic absorption spectrometry

\begin{abstract}
A B S T R A C T
A simple and fast separation of cadmium $(\mathrm{Cd})$ based on functionalized carbon nanotubes with 2,3-dimercapto-1-propanol (CNTs@DHSP) was achieved in water samples before a determination by atom trap flame atomic absorption spectrometry (AT-FAAS). In this study, $\mathrm{Cd}(\mathrm{II})$ ions were extracted by syringe filter membrane-micro solid phase extraction procedure(SFM- $\mu$-SPE). Firstly, $20 \mathrm{mg}$ of the CNTs@DHSP as solid-phase added to $20 \mathrm{~mL}$ of water sample in a syringe, then dispersed for $3 \mathrm{~min}$ after adjusting $\mathrm{pH}$ up to 7 and pass through SFM very slowly. After extraction, the Cd(II) ions were back-extracted from SFM/CNTs@DHSP by $1.0 \mathrm{~mL}$ of eluent in acidic $\mathrm{pH}$. Finally, the cadmium concentration was measured by AT-FAAS. Under the optimal conditions, the linear range $(2-90 \mu \mathrm{g}$ $\left.\mathrm{L}^{-1}\right)$, LOD $\left(0.75 \mu \mathrm{g} \mathrm{L}^{-1}\right)$ and enrichment factor (19.6) were obtained $(\mathrm{RSD}<1.5 \%)$. The adsorption capacity of Cd(II) with the CNTs@ DHSP was obtained about $152.6 \mathrm{mg} \mathrm{g}^{-1}$. The method was validated by certified reference materials (SRM, NIST) and ET-AAS in water samples.
\end{abstract}

\section{Introduction}

Cadmium (Cd) as a toxic non-essential metal release from industrial activity to water, soil, food, agricultural product and air, then, cadmium ions cause to environmental and human health hazards. Cadmium is naturally creating in the environment matrixes from agricultural and chemical industrial sources. The sources of cadmium have various applications in different industry such as PVC products in petrochemical industries, pigments in color factories, and Ni-Cd batteries [1,2]. The cadmium enters to the human body through

\footnotetext{
*Corresponding Author: Jamshid Rakhtshah

Email: jamshid_rakhtshah@yahoo.com

https://doi.org/10.24200/amecj.v4.i01.132
}

gastrointestinal and respiratory tract system from food, water, air pollution and smoking. The cadmium exposure causes to hepatic dysfunction, the pulmonary edema, the testicular damage, the osteoporosis and cancer in different organs such as, breast, renal, lung and pancreas [3,4]. The Cd ions absorb through the respiratory tract or the gastrointestinal tract and enters into the bloodstream via erythrocytes and accumulated in the kidneys liver [5]. Cadmium ions excrete from the human body through urine. The liver and kidneys are able to synthesize metallothioneins (MT) which protect the cells from cadmium toxicity through bonding to cadmium (Cd- MT) [6]. Mitochondria play a crucial role in the formation of ROS (reactive oxygen species) for cadmium [7]. Moreover, the different methodologies 
such as microbial fermentation based on $\mathrm{TiO}_{2}$ nanoparticles have been used to remove cadmium from waters efficiently $[8,9]$. The cytotoxic effects of cadmium cause to apoptotic effect in human which was reported by international Agency for research on cancer (IARC) [10]. Itai itai disease or osteomalacia is chronic cadmium poisoning was reported in Japan. The cadmium intake to the human body is about $7 \mu \mathrm{g}$ $\mathrm{Cd}$ per week. This value cause to create the cadmium concentration in renal and urine between 100-200 $\mu \mathrm{g}$ $\mathrm{g}^{-1}$ and less than $0.5 \mu \mathrm{g} \mathrm{g}^{-1}$ creatinine, respectively. Blood and urinary cadmium at $0.38 \mu \mathrm{g} \mathrm{L}^{-1}$ and $0.67 \mu \mathrm{g} \mathrm{g}^{-1}$ creatinine were associated with tubular impairment. Urinary cadmium at $0.8 \mu \mathrm{g} \mathrm{g}^{-1}$ creatinine was associated with glomerular impairment [11]. So, the extraction and determination of $\mathrm{Cd}(\mathrm{II})$ in waters is very important, due to the environment and human health safety. Recently, various analytical techniques can be used for cadmium extraction in different water, foods and environmental samples. The various methods such as flame atomic absorption spectrometry (AAS) [12], the optical microscopy based on laser-induced photoluminescence (UVVIS-NIR) [13], the $\mathrm{SrFe}_{12} \mathrm{O}_{19} @$ CTAB magnetic nanoparticles with electrothermal atomic absorption spectrometry (ET-AAS) [14-17], the colorimetric sensor [18], the electrothermal vaporization coupled with optical emission spectrometry with inductively coupled plasma (ETV-ICP-OES) [19] and laserinduced breakdown spectroscopy (LIBS) [20] were used for cadmium determination in various environmental samples. Due to the low concentration of cadmium in water samples and difficulty matrixes in wastewater samples, the pretreatment is required before the determination of cadmium by instrumental analysis. The different extraction methods such as, the ultrasound-assisted liquid-liquid spray extraction (USA-LLSE) [21], the solvent extraction [22], the liquid-liquid extraction [23], the cloud point assisted dispersive ionic liquid-liquid microextraction [24] the dispersive solid-phase extraction (DSPE) combined with ultrasound-assisted emulsification microextraction [25], solid-phase extraction (SPE) [26, 27], the coagulating homogenous dispersive micro solid-phase extraction exploiting graphene oxide nanosheets (CHD- $\mu \mathrm{SPE})[28]$ and graphene oxide-packed micro-column solid-phase extraction[29] were used before cadmium analysis in water samples. Recently, the membrane micro solidphase extraction procedure (M- $\mu$-SPE) was reported as micro SPE ( $\mu$-SPE) for separation/determination of cadmium in water samples. This method showed several advantages, such as easy and fast extraction of cadmium in water samples. The properties of adsorbents have a main role for cadmium extraction by the syringe filter membrane micro solid-phase extraction procedure (SFM- $\mu$-SPE). In this study, a novel sorbent based on CNTs@DHSP was used for extraction of $\mathrm{Cd}(\mathrm{II})$ in water and wastewater samples by SFM- $\mu$-SPE at $\mathrm{pH}$ of 7. The proposed method was validated with CRM and spike samples in waters and high recovery was obtained by AT-FAAS.

\section{Experimental}

\subsection{Material and Methods}

Atom trap flame atomic absorption spectrophotometer (GBC 932, AT-FAAS, Aus) was used for cadmium determination in water and wastewater samples. The atom trap accessory /air-acetylene controlled by AVANTA software which was placed on the airacetylene burner. The cadmium determines in water and wastewater samples with $1.0 \mathrm{~mL}$ of the sample with LOD of $0.025 \mathrm{mg} \mathrm{L}^{-1}$, the wavelength of 283.3 $\mathrm{nm}$ and $5 \mathrm{~mA}$. The lower limit of quantitation (LLOQ), ULOQ and linear range for AT-FAAS was obtained $100 \mu \mathrm{g} \mathrm{L} \mathrm{L}^{-1}, 1800 \mu \mathrm{g} \mathrm{L^{-1 }}$ and 100$1800 \mu \mathrm{g} \mathrm{L}^{-1}$, respectively. All water samples were injected by an auto-sampler to the injector of ATFAAS for 1-1.5 min. The electrothermal atomic absorption spectrophotometer (ET-AAS) was used for the validation of water samples in ultratrace analysis of $\mathrm{Cd}(\mathrm{II})$. The Metrohm $\mathrm{pH}$ meter was used for measuring $\mathrm{pH}$ in water samples (E744, Switzerland). The shacking of water samples was used based on $250 \mathrm{rpm}$ speeds by vortex mixer (Thermo, USA). The standard solution of cadmium $\left(\mathrm{Cd}^{2+}\right)$ was purchased from Sigma Aldrich. (Germany) with a concentration of $1000 \mathrm{mg} \mathrm{L}^{-1}$ in $1 \% \mathrm{HNO}_{3}$. The various concentration of cadmium was daily prepared by dilution of the standard $\mathrm{Cd}$ 
solution with DW. Ultrapure water was purchased from Millipore Company (USA) for the dilution of water samples. 2,3-Dimercapto-1-propanol (CASN:59-52-9, $\quad \mathrm{HOCH}_{2} \mathrm{CH}(\mathrm{SH}) \mathrm{CH}_{2} \mathrm{SH}$ ) was prepared from Sigma Aldrich, Germany. The $\mathrm{pH}$ was adjusted $\mathrm{pH}$ by $0.2 \mathrm{~mol} \mathrm{~L}^{-1}$ of sodium phosphate buffer solution (Merck, Germany) for a $\mathrm{pH}$ of 7.0 $\left(\mathrm{Na}_{2} \mathrm{HPO}_{4} / \mathrm{NaH}_{2} \mathrm{PO}_{4}\right)$. The analytical grade of reagents such as $\mathrm{HNO}_{3}, \mathrm{HCl}$, acetone, and ethanol were prepared from Merck, Germany. The syringe Whatman filter membrane (SFM) with glass microfiber pre-filter (100 nm, Anotop filters, SN: WHA68091112, D:10 mm, polypropylene housing polypropylene membrane) was purchased from Sigma Aldrich, Germany. Anotop syringe filters contain the proprietary alumina and use for difficult separation samples.

\subsection{Human sample preparation}

The glass analysis was washed with a $\mathrm{HNO}_{3}$ solution $(1 \mathrm{M})$ for at least $12 \mathrm{~h}$ and rinsed 10 times with DW. The cadmium concentrations in water and wastewater have a low concentrations less than $50 \mu \mathrm{g} \mathrm{L}^{-1}$ and low contamination for sampling and determination caused to low accuracy of results. By procedure, $20 \mathrm{~mL}$ of the water samples were prepared from well water, drinking water and wastewater factories from Iran. Clean syringes were prepared for sample treatment. The water is prepared and stored by standard method for sampling from water by adding nitric acid to waters.

\subsection{Synthesis of CNTs@DHSP adsorbent}

First, the CNTs@COOH was prepared according to the acid oxidation method reported in the literature [30]. In the final step, 1 g of CNTs@COOH was added in $50 \mathrm{~mL}$ of methanol and maintained under ultrasonic conditions for $15 \mathrm{~min}$. Sodium borohydride was also simultaneously added to the solution. Then, the mixture was stirred at room temperature for $3 \mathrm{~h}$. Then, the product was washed with methanol three times and dried under vacuum. Typically, CNTs@OH (0.5 g) and dry xylene (40 $\mathrm{mL}$ ) were sonicated for 15 minutes in a $100 \mathrm{~mL}$ round-bottomed flask. $3 \mathrm{~mL}$ of (3-chloropropyl) trimethoxysilane (CPTMS) was added to the above mixture, drop by drop, at room temperature. After sonicating for $15 \mathrm{~min}$, the resulting mixture was refluxed at $60{ }^{\circ} \mathrm{C}$ under $\mathrm{N}_{2}$ atmosphere to remove the produced $\mathrm{HCl}$. In order to obtain the CNTs@ $\mathrm{Cl}$, it was dried at $100{ }^{\circ} \mathrm{C}$ under vacuum. Then, $1 \mathrm{~g}$ of CNTs@Cl and $1 \mathrm{~mL}$ of DMP were mixed in $60 \mathrm{~mL}$ ethanol using an ultrasonic bath for $30 \mathrm{~min}$. Then, a few drops of triethylamine were added to the above slurry, and the mixture was refluxed at $60{ }^{\circ} \mathrm{C}$ for three extra hours. The product was separated from the reaction mixture by a PTFE membrane filter and washed with ethanol three times and finally dried under vacuum at $100{ }^{\circ} \mathrm{C}$.

\subsection{Extraction Procedure}

By SFM- $\mu$-SPE procedure, $20 \mathrm{~mL}$ of water and standard samples $\left(3 \mu \mathrm{g} \mathrm{L}^{-1}\right.$ and $\left.90 \mu \mathrm{g} \mathrm{L}^{-1}\right)$ were used for the separation and determination of cadmium ions at pH 7. Firstly, the CNTs@DHSP added to water or cadmium standard solution and shaked for $3 \mathrm{~min}$ at $\mathrm{pH}=7$. Then, the water sample was slowly passed through SFM with glass microfiber pre-filter and the solid-phase was separated by filtering (100 nm, polypropylene housing polypropylene membrane). After shaking, the Cd(II) ions were extracted by sulfur group of CNTs@DHSP as coordination bond or dative bond at pH from 6-8 ( $\mathrm{Cd}^{2+} \rightarrow$ : SH @CNTs $)$ and then the Cd (II) ions on SFM/CNTs@DHSP back-extracted by $0.5 \mathrm{~mL}$ of eluent $\left(1.5 \mathrm{M}, \mathrm{HNO}_{3}\right)$ at $\mathrm{pH}$ 2. Finally, the cadmium concentration in remained solution was determined by AT-FAAS after dilution with DW up to $1 \mathrm{~mL}$ (Fig.1). The procedure was used for a blank solution without cadmium ten times. The calibration curve for $\mathrm{Cd}$ in standards solutions was prepared (3- $90 \mu \mathrm{g} \mathrm{L}^{-1}$ ) and enrichment factor (EF) was calculated. The analytical parameters showed in Table 1. Validation of methodology was achieved by CRM for cadmium samples and ETAAS analysis. The recovery was obtained for cadmium by equation 1 . The $C_{p}$ and $C_{f}$ is the primary and final concentration of $\mathrm{Cd}(\mathrm{II})$, which was determined by SFM- $\mu$-SPE procedure coupled to AT-FAAS ( $\mathrm{n}=10$, Eq. 1).

$\operatorname{Re}(\%)=\left(\mathrm{C}_{\mathrm{p}}-\mathrm{C}_{\mathrm{f}}\right) / \mathrm{C}_{\mathrm{p}} \times 100$ 
Table 1. The analytical features for determination cadmium by SFM- $\mu$-SPE procedure

\begin{tabular}{ll}
\hline Features & value \\
\hline Working pH & $6-8$ \\
Amount of CNTs@DHSP $(\mathrm{mg})$ & 20.0 \\
Sample volume of water $(\mathrm{mL})$ & 20.0 \\
Volume of sample injection $(\mathrm{mL})$ & 1.0 \\
Linear range for water $\left(\mu \mathrm{g} \mathrm{L}^{-1}\right)$ & $3.0-90$ \\
working range for water $\left(\mu \mathrm{g} \mathrm{L}^{-1}\right)$ & $3.0-170$ \\
Mean RSD \%, $\mathrm{n}=10$ & 1.5 \\
LOD $\left(\mu \mathrm{g} \mathrm{L}^{-1}\right)$ & 0.75 \\
Enrichment factor for water & 19.6 \\
Volume and concentration of $\mathrm{HNO}_{3}$ & $1 \mathrm{~mL}, 1.5 \mathrm{M}$ \\
Shaking time & $3.0 \mathrm{~min}$ \\
Correlation coefficient & $\mathrm{R}^{2}=0.9998$ \\
\hline
\end{tabular}

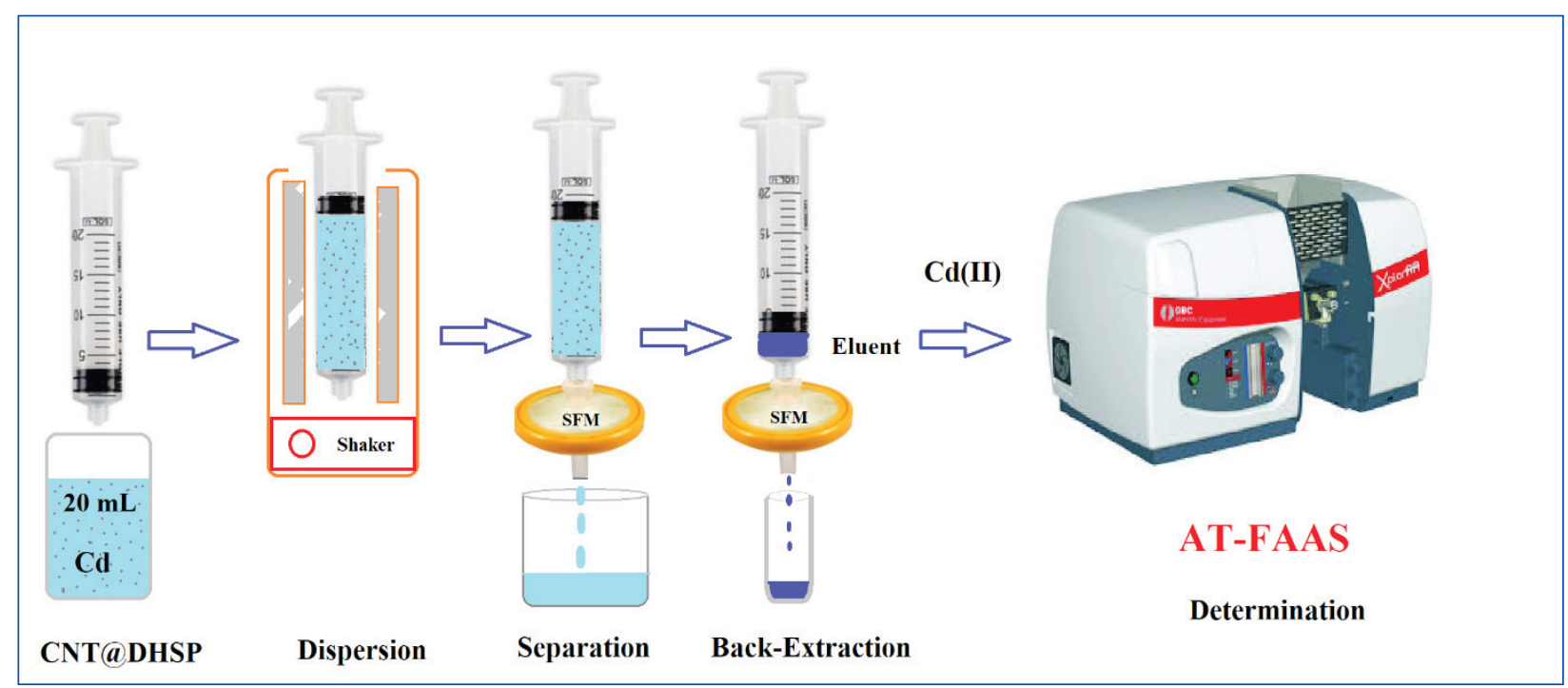

Fig. 1. Cadmium extraction in water sample based on CNTs@DHSP by SFM- $\mu-S P E$ procedure

\section{Results and discussion}

\subsection{Extraction Mechanism}

The carboxylic acid-functionalized CNTs were synthesized by using the acid oxidation method. Then, for the generation of $\mathrm{OH}$ groups on surface CNT, these materials were treated with sodium borohydride in methanol. Afterward, hydroxyl- functionalized CNTs were functionalized by (3-chloropropyl) trimethoxysilane (CPTMS) to provide chloroalkylsilane. Finally, thiol derivative as a DHSP was covalently immobilized on CNTs. Finally, SH group of DHSP on the surface of CNTs can be complexed with cadmium ions in a water solution (Fig.2). 


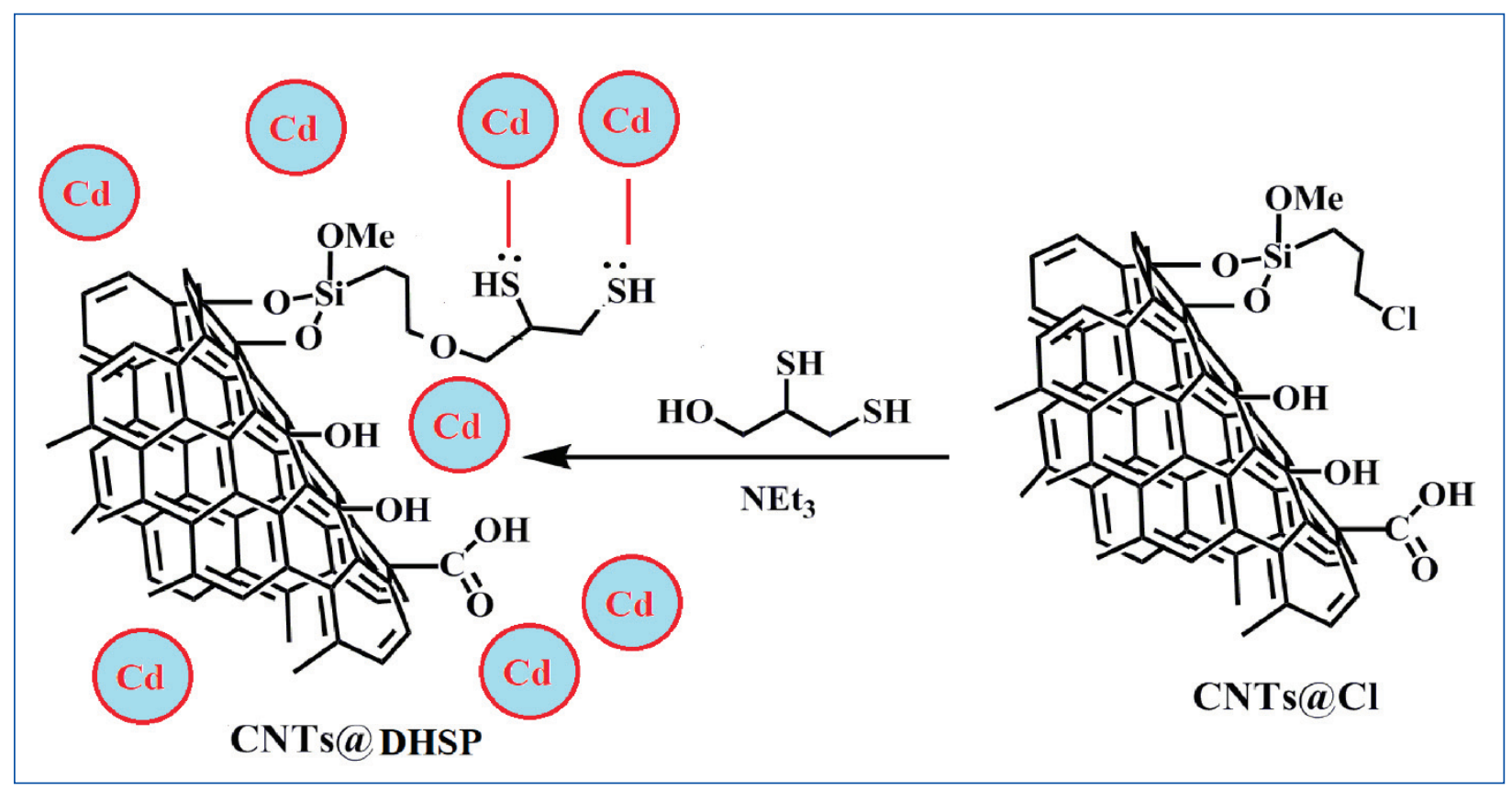

Fig. 2. The extraction mechanism of cadmium by CNTs@DHSP

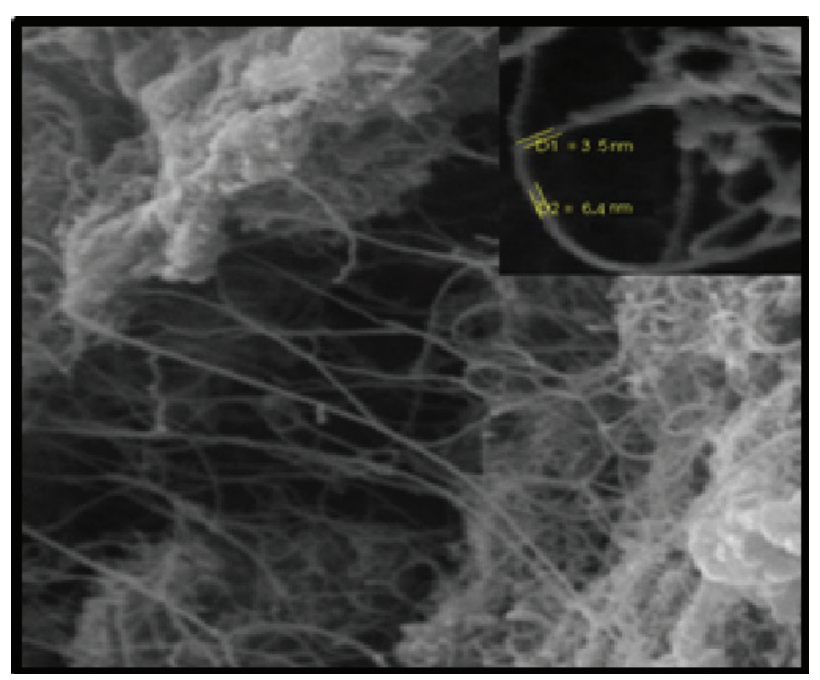

Fig.3a. SEM image of CNTs@DHSP

\subsection{SEM and TEM analysis}

The nanotubes of CNTs syntheses in University of Tabriz (Iran) and used for the synthesis of 2,3-dimercapto-1-propanol immobilized on CNTs (CNTs@DHSP). The Scanning Electron Microscopy (SEM) and Transmission Electron Microscopy (TEM) of CNTs@DHSP showed low nanoparticles size between 40-100 nm which was shown in Figures $3 a$ and $3 b$.

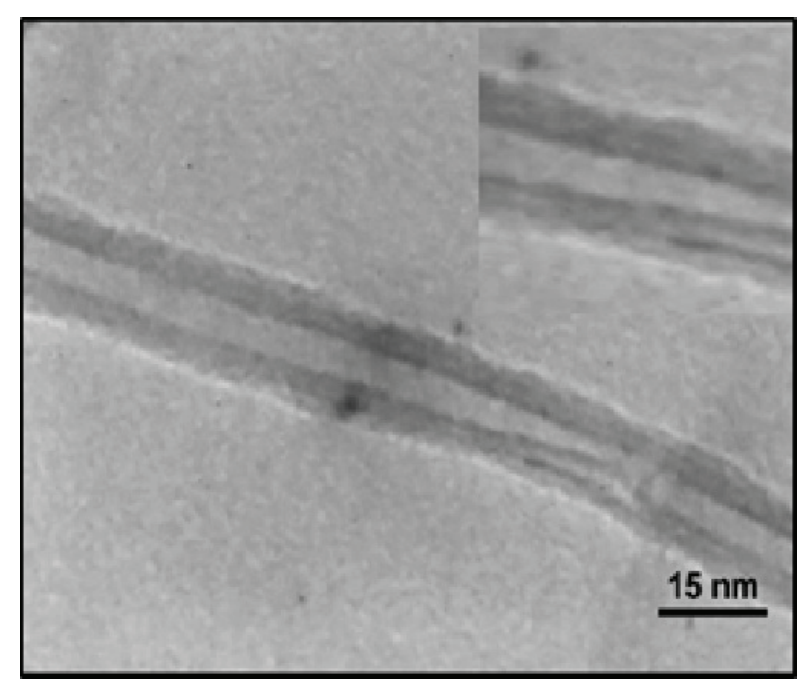

Fig.3b. TEM image of CNTs@DHSP

\subsection{Optimization of cadmium extraction SFM- $\mu$-SPE procedure}

The SFM- $\mu$-SPE procedure based on novel CNTs@ DHSP was optimized for cadmium extraction in water samples. So, different parameters such as pH,CNTs@DHSP Mass, eluent, sample volume and sonication time were studied. 


\subsubsection{The effect of $\mathrm{pH}$}

The effect of various $\mathrm{pH}$ was studied from 2 to 10 for Cd(II) extraction in water samples. The results showed the CNTs@DHSP can be removed cadmium ions from water samples at $\mathrm{pH}$ between 6 to 8. Moreover, the efficient extraction was achieved for cadmium ions at $\mathrm{pH}=7(>95 \%)$ and the recoveries reduced at $6>\mathrm{pH}$ and $\mathrm{pH}>8.5$. So, the $\mathrm{pH}$ of 7.0 was used as optimum $\mathrm{pH}$ for cadmium extraction in waters for further works (Fig. 4). The mechanism of cadmium extraction depended on the coordination bond or dative covalent bond of the thiol group in CNTs@DHSP adsorbent $(\mathrm{Cd} \rightarrow: \mathrm{SH})$. The positively charge of $\mathrm{Cd}^{2+}$ adsorbed on the surface of adsorbent with negative charge at optimized $\mathrm{pH}$. At low $\mathrm{pH}\left(\mathrm{pH}<\mathrm{pH}_{\mathrm{PZC}}\right)$, the surface of CNTs@DHSP has a positive charge. Therefore, low recovery is related to the electrostatic repulsion between $\mathrm{Cd}^{2+}$ and positive charge of CNTs@DHSP. In addition, at a pH of 7, the surface of CNTs@ DHSP have negatively charged and absorbed $\mathrm{Cd}^{2+}$. Also, in the $\mathrm{pH}>8.5$, the $\mathrm{Cd}$ ions participated as $\mathrm{OH}$ group and the recovery was decreased.

\subsubsection{Effect of CNTs@DHSP mass}

The efficient extraction was obtained by optimizing of CNTs@DHSP mass in pH=7. Therefore, the various of CNTs@DHSP mass was studied between $5-50 \mathrm{mg}$ for $\mathrm{Cd}(\mathrm{II})$ extraction by SFM$\mu$-SPE procedure. The results showed us, a high recovery of more than $95 \%$ was achieved for 18 mg of CNTs@DHSP in water samples. So, 20 mg of CNTs@DHSP as optimum adsorbent mass was used for the experimental run. (Fig. 5). Based on Figure 6, The higher amount of CNTs@DHSP had no effect on cadmium recovery.

\subsubsection{Effect of eluent and sample volume on cadmium extraction}

The volume and concentration of eluent for back extraction cadmium ions from SFM/CNTs@, DHSP adsorbent were optimized at $\mathrm{pH}=7$. Acidic $\mathrm{pH}$ dissociated thiol binding to cadmium and caused to release of free cadmium ions into the eluent phase. The different acid solution such as $\mathrm{HCl}, \mathrm{HNO}_{3}, \mathrm{NaOH}$ and $\mathrm{H}_{2} \mathrm{SO}_{4}$, was selected for back-extraction of cadmium from SFM/CNTs@,

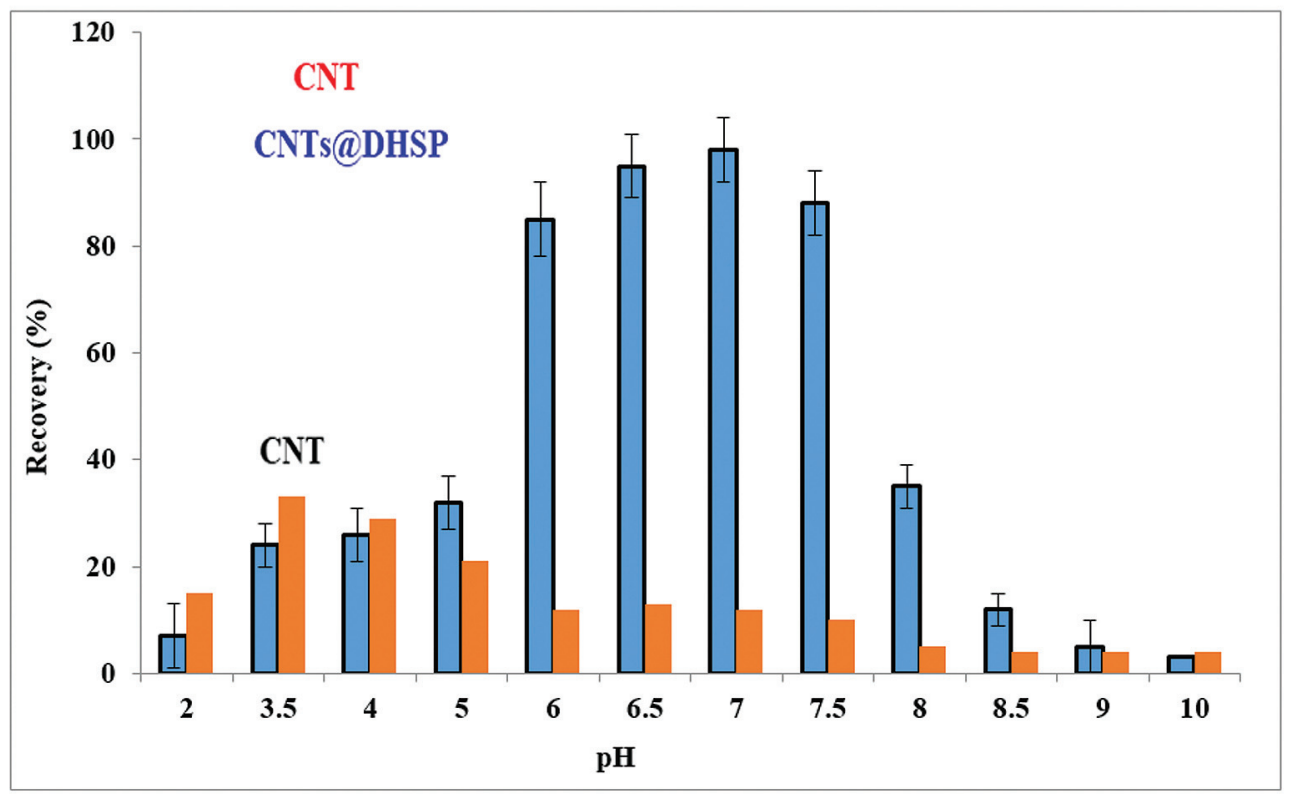

Fig. 4. The effect of $\mathrm{pH}$ on cadmium extraction based on CNTs@DHSP by SFM- $\mu$-SPEprocedure 


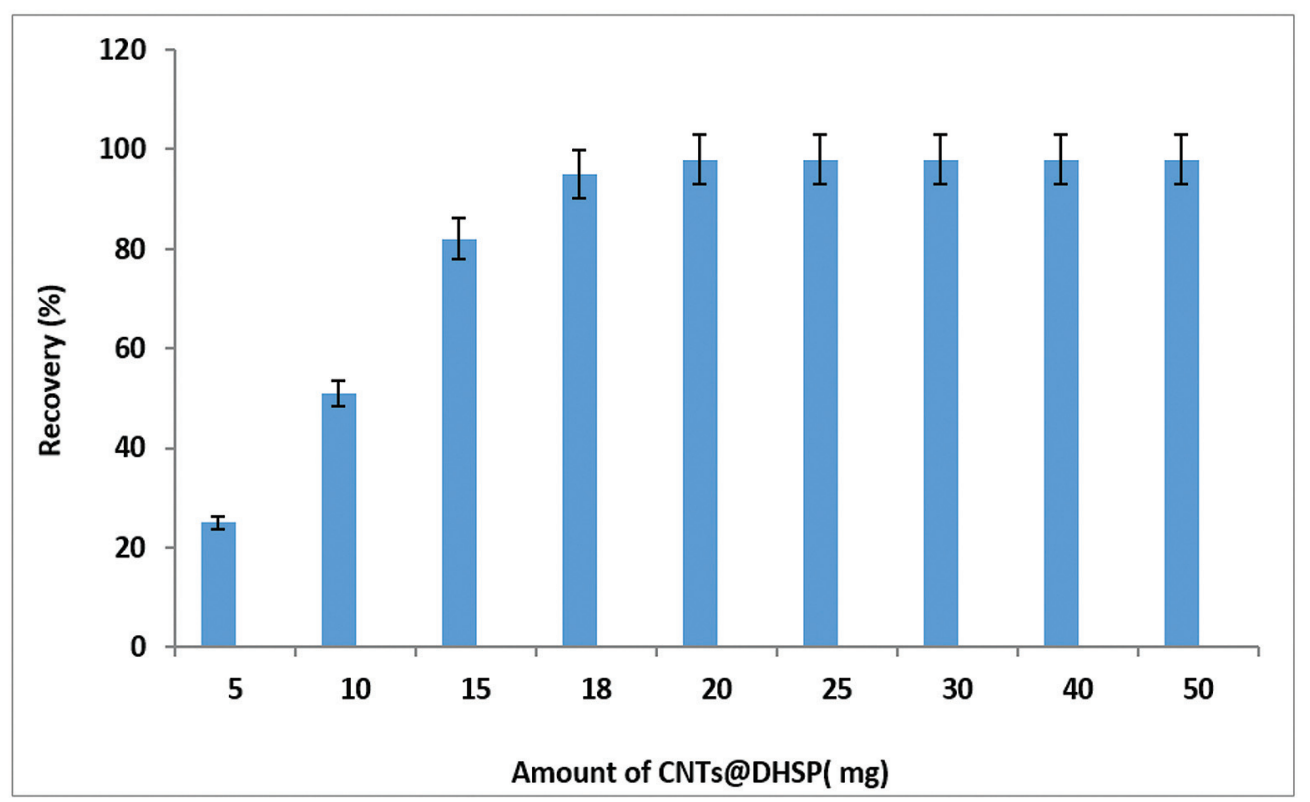

Fig. 5. The effect of CNTs@DHSP amount on cadmium extraction by SFM- $\mu$-SPE procedure

DHSP adsorbent. The results showed that $1.5 \mathrm{~mol}$ $\mathrm{L}^{-1} \mathrm{HNO}_{3}$ was quantitatively back-extracted the cadmium from SFM/CNTs@DHSP adsorbent. The sample volume between 1-100 $\mathrm{mL}$ for cadmium extraction was studied in water samples by SFM$\mu$-SPE procedure. For optimization, the cadmium concentration ranges (3-90 $\left.\mu \mathrm{g} \mathrm{L}^{-1}\right)$ based on $20 \mathrm{mg}$ of CNTs@DHSP adsorbent were examined by the proposed procedure. The results showed us the high recoveries were achieved $25 \mathrm{~mL}$ of water samples at $\mathrm{pH}=7$. Therefore, $20 \mathrm{~mL}$ of water was used as the optimal value for further study.

\subsubsection{Effect of sonication time and adsorption capacity}

The extraction time depended on the dispersion of nanoparticles CNTs@DHSP adsorbent in the water samples and caused to increase interaction between HS with $\mathrm{Cd}(\mathrm{II})$ at $\mathrm{pH}=7$. The effect of sonication time was studied from 0.5 to $5 \mathrm{~min}$. It was observed that the sonication of $3.0 \mathrm{~min}$ had favorite extraction for cadmium in water samples.
The absorption capacities of cadmium for CNTs@ DHSP and CNTs adsorbents were evaluated in optimized conditions. First, 20 mg of CNTs@ DHSP or CNTs adsorbents added to $20 \mathrm{~mL}$ of water sample (standards cadmium solution: $200 \mathrm{mg} \mathrm{L}^{-1}$ ) at $\mathrm{pH}$ 7. After sonication for $20 \mathrm{~min}$, the cadmium extracted on the CNTs@DHSP or CNTs adsorbents at optimizing $\mathrm{pH}$. The cadmium concentration in the liquid phase is directly determined as the final cadmium concentration after adsorption processes. The results showed the adsorption capacity for the CNTs@DHSP or CNTs adsorbents was obtained $152.6 \mathrm{mg} \mathrm{g}^{-1}$ and $19.7 \mathrm{mg} \mathrm{g}^{-1}$, respectively.

\subsubsection{Interference of coexisting ions}

The effect of interference ions on cadmium extraction based on CNTs@DHSP adsorbent in water samples was studied by SFM- $\mu$-SPE procedure. The various interfering ions were added to $20 \mathrm{~mL}$ of cadmium solution (ULOQ: $90 \mu \mathrm{g} \mathrm{L}^{-1}$ ) at $\mathrm{pH}$ 7. Based on results the most of the probable concomitant ions have no effect on the extraction recovery of Cd(II) ions in optimized conditions (Table 2). 
Table 2. The effect of interferences ions on cadmium extraction in water samples by SFM- $\mu$-SPE procedure

\begin{tabular}{lcc}
\hline & Mean ratio $\left(\mathbf{C}_{\mathbf{I}} / \mathbf{C}_{\mathbf{C d}(\mathrm{II})}\right)$ & Recovery (\%) \\
\cline { 2 - 3 } Interfering Ions (I) & $\mathbf{C d}(\mathbf{I I})$ & $\mathbf{C d}(\mathbf{I I})$ \\
\hline $\mathrm{Al}^{3+}, \mathrm{V}^{3+}$ & 600 & 96.8 \\
$\mathrm{Zn}^{2+}, \mathrm{Cu}^{2+}$ & 900 & 08.0 \\
$\mathrm{I}^{-}, \mathrm{Br}^{-}, \mathrm{F}^{-}, \mathrm{Cl}^{-}$ & 1200 & 99.2 \\
$\mathrm{Na}^{+}, \mathrm{K}^{+}$ & 1000 & 98.4 \\
$\mathrm{Ca}^{2+}, \mathrm{Mg}^{2+}$ & 900 & 97.7 \\
$\mathrm{CO}_{3}^{2-}, \mathrm{PO}_{4}^{3-}$ & 1000 & 97.2 \\
$\mathrm{Co}^{2+}, \mathrm{Mn}^{2+}, \mathrm{Sn}^{2+}$ & 350 & 98.3 \\
$\mathrm{Ni}^{2+}$ & 150 & 96.7 \\
$\mathrm{NH}_{4}^{+}, \mathrm{NO}^{-}$ & 800 & 98.5 \\
$\mathrm{Hg}^{2+}$ & 100 & 97.4 \\
\hline
\end{tabular}

\subsubsection{Real samples analysis}

The separation and determination of cadmium in water samples was done based on CNTs@DHSP adsorbent by the SFM- $\mu$-SPE procedure. The results showed us, the cadmium was efficiently extracted by the thiol group of CNTs@DHSP adsorbent in water samples at $\mathrm{pH}=7$. By spiking water samples, the accuracy of the results was satisfactorily validated at optimized $\mathrm{pH}$ and confirmed that the SFM- $\mu$-SPE procedure could be efficiently extracted/determined cadmium in water samples (Table 3). Due to results, the high recovery for extraction cadmium in water and wastewater samples was achieved by nanoparticles of CNTs@DHSP. Moreover, the certified reference materials (NIST; CRM) were used for validating results by the SFM- $\mu$-SPE procedure (Table 4). Also, the results were validated by ET-AAS analysis which was compared to SFM- $\mu$-SPE/AT-FAAS (Table 5).

Table 3. Validation of SFM- $\mu$-SPE/AT-AAS procedure for Cd(II) determination in waters by spiking of real samples

\begin{tabular}{|c|c|c|c|}
\hline Sample* & $\operatorname{Added}\left(\mu g \mathrm{~L}^{-1}\right)$ & ${ }^{*}$ Found $\left(\mu \mathrm{g} \mathrm{L}^{-1}\right)$ & Recovery (\%) \\
\hline \multirow{2}{*}{ Water A } & --- & $4.23 \pm 0.18$ & --- \\
\hline & 4.0 & $8.14 \pm 0.31$ & 97.8 \\
\hline \multirow{2}{*}{ Water B } & --- & $2.03 \pm 0.09$ & --- \\
\hline & 2.0 & $3.98 \pm 0.21$ & 97.5 \\
\hline \multirow{2}{*}{ Water C } & --- & ND & --- \\
\hline & 2.0 & $1.93 \pm 0.08$ & 96.5 \\
\hline \multirow{2}{*}{ Wastewater A } & --- & $50.75 \pm 1.23$ & --- \\
\hline & 40 & $88.83 \pm 2.64$ & 95.2 \\
\hline \multirow{2}{*}{ Wastewater B } & --- & $48.32 \pm 1.87$ & --- \\
\hline & 40 & $89.56 \pm 3.45$ & 103.1 \\
\hline \multirow[t]{2}{*}{ Wastewater C } & --- & $29.56 \pm 1.34$ & --- \\
\hline & 30 & $57.95 \pm 2.08$ & 94.6 \\
\hline
\end{tabular}

*Mean of three determinations of samples \pm confidence interval $(\mathrm{P}=0.95, \mathrm{n}=5)$

Water A: Varamin River; Water B: Karaj River; Water C: drinking water Tehran; Wastewater A: Paint Factory of Karaj; Wastewater B: Petrochemical waste; Wastewater C: Chemical Factory in Industrial Varamin Co. 
Table 4. Validation of SFM- $\mu$-SPE procedure for cadmium determination by certified reference materials in waters (CRM, NIST)

\begin{tabular}{lcccc}
\hline Sample & conc. $\left(\boldsymbol{\mu g} \mathbf{L}^{-1}\right)$ & Added & Found $^{*}\left(\boldsymbol{\mu g ~ \mathbf { L } ^ { - 1 } )}\right.$ & Recovery (\%) \\
\hline SRM 1643f & $5.89 \pm 0.13$ & ---- & $5.82 \pm 0.16$ & ----- \\
& & 5.0 & $10.79 \pm 0.25$ & 99.4 \\
\hline SRM 3108 & $50.10 \pm 1.1$ & ---- & $48.77 \pm 1.42$ & ----- \\
& & 40 & $87.64 \pm 2.61$ & 97.2 \\
\hline
\end{tabular}

*Mean of three determinations of samples \pm confidence interval $(\mathrm{P}=0.95, \mathrm{n}=10)$

SRM 3108: Certified Cadmium Mass Fraction: $10.007 \mathrm{mg} \mathrm{g}^{-1} \pm 0.027 \mathrm{mg} \mathrm{g}^{-1}$ dissolved in $1 \mathrm{~L} \mathrm{DW}\left(\mathrm{C}=10 \mathrm{mg} \mathrm{L}^{-1}\right)$, make by dilution DW up to $0.05 \mathrm{mg} \mathrm{L}^{-1}$.

Table 5. Comparing of SFM- $\mu$-SPE procedure with ET-AAS for cadmium determination in water samples

\begin{tabular}{|c|c|c|c|c|}
\hline Sample & Added $\left(\mu g L^{-1}\right)$ & ET-AAS* $\left(\mu g L^{-1}\right)$ & $\operatorname{AT}^{-F A A S}{ }^{*}\left(\mu g L^{-1}\right)$ & Recovery (\%) \\
\hline \multirow[t]{2}{*}{ Water A } & ----- & $4.18 \pm 0.17$ & $4.06 \pm 0.13$ & ----- \\
\hline & 4.0 & ---- & $7.98 \pm 0.24$ & 98.0 \\
\hline \multirow[t]{2}{*}{ Water B } & ---- & $2.12 \pm 0.11$ & $2.18 \pm 0.08$ & ----- \\
\hline & 2.0 & ----- & $4.09 \pm 0.16$ & 95.5 \\
\hline \multirow[t]{2}{*}{ Water C } & ----- & $0.25 \pm 0.02$ & ${ }^{\mathrm{a}} \mathrm{ND}$ & ----- \\
\hline & 2.0 & ----- & $1.97 \pm 0.09$ & 98.5 \\
\hline \multirow[t]{2}{*}{ Well water } & ----- & $6.12 \pm 0.28$ & $5.94 \pm 0.18$ & ----- \\
\hline & 5.0 & ----- & $11.03 \pm 0.34$ & 101.8 \\
\hline
\end{tabular}

*Mean of three determinations of samples \pm confidence interval $(P=0.95, \mathrm{n}=10)$

${ }^{a}$ ND: Not Detected

\section{Conclusions}

A novel CNTs@DHSP nanostructure was used for cadmium extraction/separation/determination in water samples by the SFM- $\mu$-SPE method coupled with AT-FAAS. By the proposed procedure, the efficient/ easy/fast extraction for cadmium was obtained in a short time at $\mathrm{pH}=7$. The CNTs@DHSP nanostructure has excellent recovery for $\mathrm{Cd}(\mathrm{II})$ extraction without any chelating ligands. The procedure had many advantages such as reusability of adsorbent, fast/easy pretreatment and a wide linear range for determination cadmium in waters. Therefore, the CNTs@DHSP nanostructure can be used as the favorite methodology for the determination and separation of cadmium in water samples by AT-FAAS.

\section{Acknowledgements}

The authors wish to thank from Department of Inorganic Chemistry, Faculty of Chemistry, University of Tabriz, Tabriz, Iran, for supporting this work.

\section{References}

[1] L.T. Friberg, G.G. Elinder, T. Kjellstrom, G.F. Nordberg, Cadmium and Health: A toxicological and epidemiological appraisal, CRC Press: Boca Raton, FL, USA, Vol. 2, 2019.

[2] M.R. Rahimzadeh, S. Kazemi, A.A. Moghadamnia, Cadmium toxicity and treatment, Caspian J. Intern. Med., 8 (2017) 135-145.

[3] A.A. Tinkov, T. Filippini, O.P. Ajsuvakovae, M.G. Skalnaya, J. Aasethf, G. Bjørklundh, E.R. Gatiatulinai, E.V. Popova, O.N. Nemereshinai, P.T. Huangk, Cadmium and atherosclerosis: A review of toxicological mechanisms and a meta-analysis of epidemiologic studies, Environ. Res., 162 (2018) 240-260.

[4] M.S. Sinicropi, A. Caruso, A. Capasso, C. Palladino, A. Panno, C. Saturnino, Heavy metals: toxicity and carcinogenicity, Pharmacol., 2 (2010) 329-333. 
[5] S. Satarug, Dietary cadmium intake and its effects on kidneys, Toxics, 6 (2018) 15.

[6] A.E. Nielsen, A. Bohr, M. Penkowa, The balance between life and death of cells: Roles of metallothioneins, Biomark. Insights, 1 (2007) 99-111.

[7] G. Gobe, D. Crane, Mitochondria, reactive oxygen species and cadmium toxicity in the kidney, Toxicol. Lett., 198 (2010) 49-55.

[8] T.Bora,J.Dutta,Applications of nanotechnology in wastewater treatment-A review, Nanosci. Nanotechnol., 14 (2014) 613-626.

[9] L. Zhang, Q. Lei, Y. Cheng, Y. Xie, H. Qian, Y. Guo, Y. Chen, W. Yao, Study on the removal of cadmium in rice using microbial fermentation method, J. Food Sci., 82 (2017) 1467-1474.

[10] International Agency for Research on Cancer (IARC), Monographs on the evaluation of the carcinogenic risks to human's beryllium, cadmium, mercury and exposures in the glass manufacturing Industry, scientific publications: Lyon, France, pp. 119-238, 1993.

[11] World Health Organization(WHO), Evaluation of certain food additives and contaminants, Thirty-third report of the joint FAO/WHO expert committee on food additives, technical report series 776, 1989. http://www.who.int/ ipcs/publications/jecfa/reports/en/index.html

[12] N. Altunay, A. Elik, Ultrasound-assisted alkanol-based nanostructured supramolecular solvent for extraction and determination of cadmium in food and environmental samples: Experimental design methodology, Microchem. J., 164 (2021) 105958.

[13] E. M. Angelin, M. Ghirardello, The multianalytical in situ analysis of cadmium-based pigments in plastics, Microchem. J., 157 (2020) 105004.

[14] V. MortazaviNik, E. Konoz, A. Feizbakhsh, A. A. M. Sharif, Simultaneous extraction of chromium and cadmium from bean samples by $\mathrm{SrFe}_{12} \mathrm{O}_{19} @ \mathrm{CTAB}$ magnetic nanoparticles and determination by ETAAS: An experimental design methodology, Microchem. J., 159 (2020) 105588.
[15] M. Arjomandi, H. Shirkhanloo, A review: Analyticalmethods for heavymetals determination in environment and human samples, Anal. Methods Environ. Chem. J., 2 (2019) 97-126.

[16] H. Shirkhanloo, S. A. H. Mirzahosseini, N. Shirkhanloo, The evaluation and determination of heavy metals pollution in edible vegetables, water and soil in the south of Tehran, province by GIS, Arch. Environ. Prot., 41 (2015) 63-72.

[17] M. Aliomrani, M.A. Sahraian, H. Shirkhanloo, M. Sharifzadeh, Blood concentrations of cadmium and lead in multiple sclerosis patients from Iran, Iran. J. Pharm. Res., 15 (4), 8252016

[18] J. Charoensuk, J. Thonglao, B. Wichaiyo, A simple and sensitive colorimetric sensor for cadmium (II) detection based on selfassembled trimethyl tetradecyl ammonium bromide and murexide on colloidal silica, Microchem. J., 160 (2021) 105666.

[19] N. S.Medvedev, O. V. Lundovskaya, A. I. Saprykin, Direct analysis of high-purity cadmium by electrothermal vaporization-inductively coupled plasma optical emission spectrometry, Microchem. J., 145 (2019) 721-755.

[20] Y. Liu, Y. Chu, Z. Hu, S. Zhang, High-sensitivity determination of trace lead and cadmium in cosmetics using laser-induced breakdown spectroscopy with ultrasound-assisted extraction, Microchem. J., 158 (2020) 105322.

[21] H. Kaw, J. Li, X. Jin, Ultrasound-assisted liquid-liquid spray extraction for the determination of multi-class trace organic compounds in high-volume water samples, Analyst, 143 (2018) 4575-4584.

[22] E. Bidari, M. Irannejad, M. Gharabaghi, Solvent extraction recovery and separation of cadmium and copper from sulphate solution, J. Environ. Chem. Eng., 1 (2018) 1269-1274.

[23] S.S. Swain, B. Nayak, N. Devi, S. Das, N. Swain, Liquid-liquid extraction of cadmium(II) from sulfate medium using phosphonium and ammonium based ionic liquids diluted in kerosene, Hydrometallurgy, 162 (2016) 63-70. 
[24] H. Shirkhanloo, M. Ghazaghi, M.M. Eskandari, Cloud point assisted dispersive ionic liquidliquid microextraction for chromium speciation in human blood samples based on isopropyl 2-[(isopropoxycarbothiolyl) disulfanyl, Anal. Chem. Res., 10 (2016) 18-27.

[25] M. Sadeghi, E. Rostami, D. Kordestani, H. Veisi, M. Shamsipur, Simultaneous determination of ultra-low traces of lead and cadmium in food and environmental samples using dispersive solid-phase extraction (DSPE) combined with ultrasound-assisted emulsification microextraction based on the solidification of floating organic drop (UAEME-SFO) followed by GFAAS, RSC Adv., 7 (2017) 27656-27667.

[26] E. Yilmaz, I. Ocsoy, Bovine serum albumin$\mathrm{Cu}(\mathrm{II})$ hybrid nanoflowers: An effective adsorbent for solid phase extraction and slurry sampling flame atomic absorption spectrometric analysis of cadmium and lead in water, hair, food and cigarette samples, Anal. Chim. Acta, 906 (2016)110-117.

[27] H. Shirkhanloo, A. Khaligh, F. Golbabaei, Z. Sadeghi, A. Vahid, A. Rashidi, On-line micro column preconcentration system based on amino bimodal mesoporous silica nanoparticles as a novel adsorbent for removal and speciation of chromium (III, VI) in environmental samples, J. Environ. Health Sci. Eng., 13 (2015) 1-12.

[28] M. Ghazaghi, H. Z. Mousavi, A. M. Rashidi, H. Shirkhanloo, R. Rahighi, Innovative separation and preconcentration technique of coagulating homogenous dispersive micro solid phase extraction exploiting graphene oxide nanosheets, Anal. Chim. Acta, 902 (2016) 33-42.

[29] H. Shirkhanloo, A. Khaligh, H.Z. Mousavi, A. Rashidi, Graphene oxide-packed microcolumn solid-phase extraction combined with flame atomic absorption spectrometry for determination of lead (II) and nickel (II) in water samples, Int. J. Environ. Anal. Chem., 95 (2015) 16-32.
[30] M. B. Hossein Abadi, H. Shirkhanloo, J. Rakhtshah, The evaluation of TerphApm@ MWCNTs as a novel heterogeneous sorbent for benzene removal from air by solid phase gas extraction, Arab. J. Chem. 13 (2020) 1741-1751. 